\title{
Correction of Sensor Saturation Effects in MODIS Oceanic Particulate Inorganic Carbon
}

\author{
Peter E. Land ${ }^{\circledR}$, Jamie D. Shutler, and Timothy J. Smyth
}

\begin{abstract}
The highly reflective nature of high particulate inorganic carbon (PIC) from calcifying plankton, such as surface blooms of Emiliana huxleyi in the latter stages of their life cycle, can cause the saturation of the Moderate Resolution Imaging Spectrometer (MODIS) visible spectrum ocean color bands. This saturation results in errors in the standard MODIS oceanic PIC product, resulting in the highest PIC levels being represented as cloud-like gaps (missing data) in daily level 2 data, and as either gaps or erroneously low PIC values in temporally averaged data (e.g., 8-day level 3 data). A method is described to correct this error and to reconstruct the missing data in the ocean color band data by regressing the $1-\mathrm{km}$ spatial resolution ocean color bands against MODIS higher resolution $(500 \mathrm{~m}$ spatial resolution) bands with lower sensitivities. The method is applied to all North Atlantic MODIS data from 2002 to 2014. This shows the effect on mean PIC concentration over the whole North Atlantic to be less than $1 \%$ annually and $2 \%$ monthly, but with more significant regional effects, exceeding $10 \%$ in peak months in some coastal shelf regions. Effects are highly localized and tend to annually reoccur in similar geographical locations. Ignoring these missing data within intense blooms is likely to result in an underestimation of the influence that coccolithophores, and their changing distributions, are having on the North Atlantic carbon cycle. We see no evidence in this 12-year time series of a temporal poleward movement of these intense bloom events.
\end{abstract}

Index Terms-Optical saturation, remote sensing, satellite applications, sea surface.

\section{INTRODUCTION}

C OCCOLITHOPHORES are the largest source of calcium carbonate in the oceans and are considered to play an important role in oceanic carbon cycles [1], [2]. The previous work has highlighted that blooms of coccolithophores can reduce the North Atlantic annual net sink of atmospheric $\mathrm{CO}_{2}$ by between $3 \%$ and $28 \%$ (dependent upon the year), as their growth increases the in-water partial pressure of $\mathrm{CO}_{2}\left(\mathrm{pCO}_{2}\right)$,

Manuscript received May 11, 2017; revised August 14, 2017; accepted September 7, 2017. The work of P. E. Land and T. J. Smyth were supported in part by the U.K. Natural Environment Research Council through projects Carbon/Nutrient Dynamics and Fluxes Over Shelf Systems under Contract NE/K002058/1 and in part by the Radiatively Active Gases from the North Atlantic Region and Climate Change under Contract NE/K002511/1. (Corresponding author: Peter E. Land.)

P. E. Land and T. J. Smyth are with the Plymouth Marine Laboratory, Plymouth PL1 3DH, U.K. (e-mail: peland@pml.ac.uk; tjsm@pml.ac.uk).

J. D. Shutler is with the Centre for Geography and Environment and Society, University of Exeter Center for Geography, Environment and Society, Cornwall TR10 9FE, U.K. (e-mail: j.d.shutler@ exeter.ac.uk).

This paper has supplementary downloadable material available at http://ieeexplore.ieee.org, provided by the author.

Color versions of one or more of the figures in this paper are available online at http://ieeexplore.iee.org.

Digital Object Identifier 10.1109/TGRS.2017.2763456
TABLE I

GLOSSARY

\begin{tabular}{|c|c|}
\hline Abbreviation & Description \\
\hline Calcite_2b & Two-band PIC (or calcite) algorithm [1] \\
\hline Calcite_3b & Three-band PIC (or calcite) algorithm [3] \\
\hline CLDICE & $\begin{array}{l}\text { Cloud/ice flag for presence of clouds or ice inferred from } \\
\text { the near infrared }\end{array}$ \\
\hline HILT & High light flag for sensor saturation in the visible bands \\
\hline L1A & $\begin{array}{l}\text { Level } 1 \mathrm{~A} \text {, raw satellite measurements expressed as digital } \\
\text { numbers }\end{array}$ \\
\hline L1B & $\begin{array}{l}\text { Level 1B, satellite data converted to top-of-atmosphere } \\
\text { radiance }\end{array}$ \\
\hline L2 & Level 2, geophysical products derived from satellite data \\
\hline L3 & Level 3, products binned spatially and temporally \\
\hline $\mathrm{L}_{\mathrm{t}}$ & Top-of-atmosphere radiance \\
\hline $\mathrm{nL}_{\mathrm{w}}$ & Normalized water-leaving radiance \\
\hline PIC & $\begin{array}{l}\text { Particulate inorganic carbon concentration }\left(\mu \mathrm{mol} \mathrm{m}^{-3}\right) \text {. } \\
\text { Also the MODIS product combining calcite_ } 2 \mathrm{~b} \text { and } \\
\text { calcite_3b. }\end{array}$ \\
\hline $\mathrm{R}_{\mathrm{RS}}$ & Remote sensing reflectance \\
\hline STLIGHT & $\begin{array}{l}\text { Stray light flag for pixels at risk of contamination by stray } \\
\text { light from nearby bright pixels }\end{array}$ \\
\hline
\end{tabular}

thus limiting the uptake of $\mathrm{CO}_{2}$ [3]. The North Atlantic is an important and highly variable natural sink of atmospheric $\mathrm{CO}_{2}$ accounting for $\sim 30 \%$ of the global oceanic uptake [4], [5]; thus, understanding and quantifying its variability is important for understanding the existing climate and any predictions of the future. When coccolithophores bloom (i.e., form in concentrations much higher than the background levels) and subsequently die they shed their platelets, or coccoliths, which are highly reflective and give the water a milky appearance making them visible from space (see [6], [7]). The spatially large areas in which these blooms form make satellite observations a key approach for studying their spatial and temporal distributions. Consequently, the detection and quantification of coccolithophore blooms using satellite ocean color sensors such as NASA's Sea-viewing Wide Field-of-view Sensor (SeaWiFS) and Moderate Resolution Imaging Spectrometer (MODIS) are an active and climatically important field of research [1], [3], [6], [8], [9].

During a particularly intense coccolithophore bloom in the Celtic Sea off the coast of France on June 15, 2004 at 13:35 GMT [shown in Fig. 1(c)], it was noted that a region of missing data appeared in the center of the bloom in a MODIS-Aqua Level 2 (L2) remote sensing reflectance $\left(R_{\mathrm{RS}}\right)$ scene [Fig. 2(c)], but this did not appear in the corresponding SeaWiFS L2 $R_{\mathrm{RS}}$ measured within a few minutes of the MODIS scene (see Table I for definition of terms). Inspection of the MODIS Level 1B (L1B) top of atmosphere radiance $L_{t}$ 


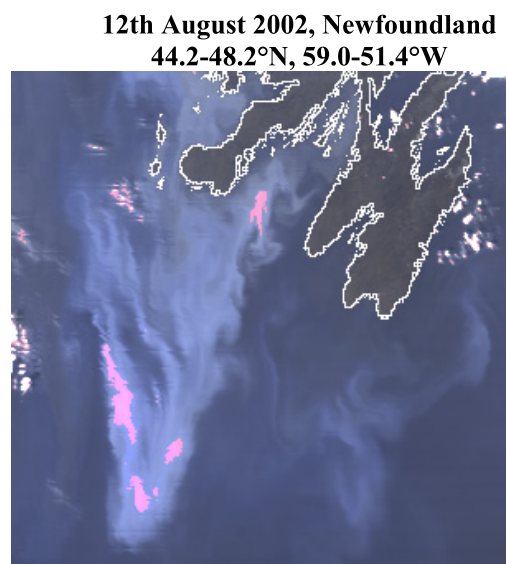

(a)

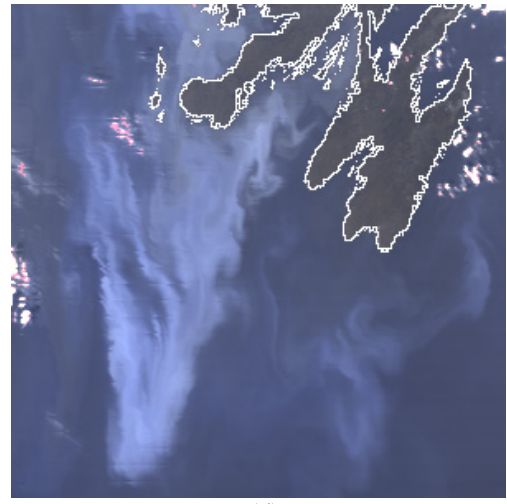

(d)

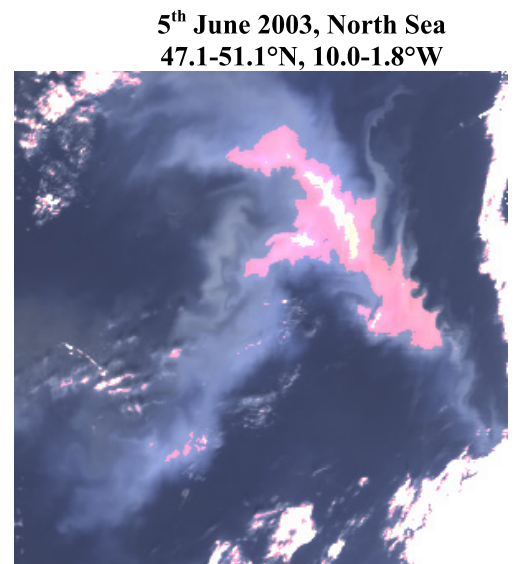

(b)

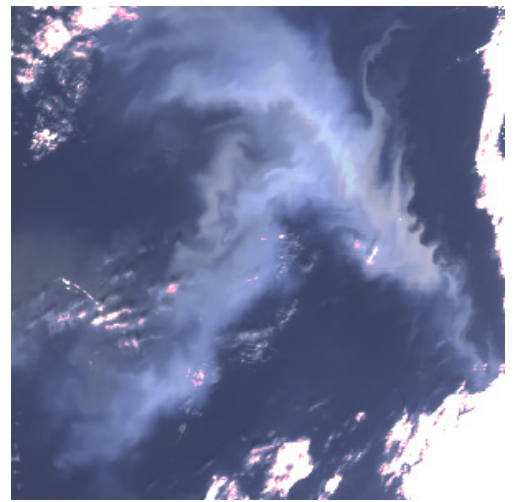

(e)

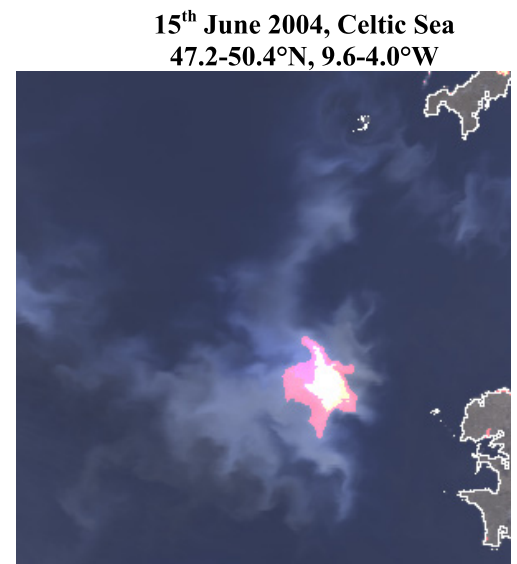

(c)

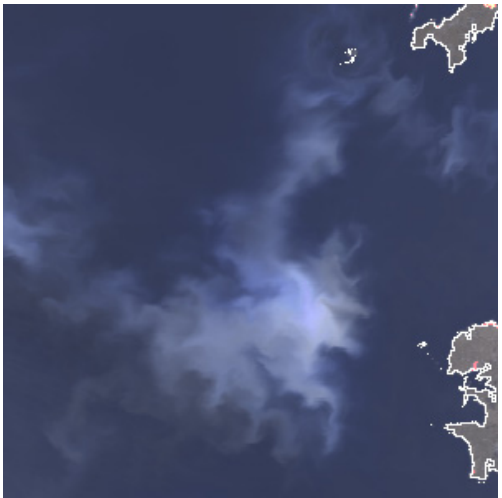

(f)

Fig. 1. Level $1 \mathrm{~B}$ radiance composites ( $\mathrm{red}=547 \mathrm{~nm}$, green $=531 \mathrm{~nm}$, and blue $=488 \mathrm{~nm}$ ). (a)-(c) Original radiances, with saturated values shown as white (all bands saturated) or pink (547 nm saturated). (d)-(f) Same composites after correction. Note that saturated values around clouds and coastlines are left uncorrected.

revealed that one or more of the MODIS visible bands was saturating in this region [Fig. 1(c)]. The MODIS ocean color processing uses a set of flags that are raised when certain conditions are met in a given pixel, for example, the presence of land, and this saturation results in the raising of the high light (HILT) flag, which by default causes the pixel to be masked at L2. This means that the particulate inorganic carbon (PIC or calcite) products, which principally measure the intensity of coccolithophore blooms, are also masked and set to zero in the most intense blooms. At Level 3 (L3) this situation is exacerbated, since pixels in close proximity to the pixels with the HILT flag raised have the stray light (STLIGHT) flag raised, and by default are masked at L3, leaving an even larger "hole" in the PIC products, exactly where PIC levels are largest. This effect may not be apparent in temporally averaged L3 composites, since a masked region in one L2 scene of a L3 composite may be covered by other scenes (with lower PIC or different viewing and illumination geometry) in which saturation does not occur. Any remaining masked areas may appear very similar to gaps due to cloud. Hence, there may be no apparent anomaly in the L3 composite, but the PIC value will be erroneously low. Saturation is less likely to occur at polar latitudes, where strong coccolithophore blooms occur but background light levels are lower, so blooms are less likely to cause saturation of the MODIS ocean color bands (see Section III).
Documented evidence of intense coccolithophore blooms at mid to low latitudes revealed two other examples of blooms in which MODIS-Aqua saturates. These were off Newfoundland on August 12, 2002 at 16:10 GMT (http://www.soes.soton.ac.uk/staff/tt/eh/nwatl.html, accessed on February 9, 2016) and the North Sea on June 5, 2003 at 12:45 GMT (http://www.soes.soton.ac.uk/staff/tt/eh/ satbloompics.html, accessed on February 9, 2016). In all three cases, MODIS saturates in three 1-km resolution ocean color bands such as 488, 531, and $547 \mathrm{~nm}$. Figs. 1(a)-(c) and 2(a)-(c) show L1B and L2 false color composites of the three cases using 547, 531, and $488 \mathrm{~nm}$ as red, green, and blue, respectively. Pink in Fig. 1(a)-(c) indicates saturation at $547 \mathrm{~nm}$, while white indicates saturation in all three bands. As noted above, saturation in any band causes the raising of the HILT flag and consequent masking of the affected pixel at L2 and surrounding pixels at L3.

In this paper, we demonstrate that it is possible to use MODIS 500-m resolution bands to replace the missing data in the $1-\mathrm{km}$ resolution ocean color bands. The 500-m bands are designed to measure land, clouds, and ice, and so have a much larger radiometric range than the ocean color bands, which are designed to more precisely measure the generally optically dark sea. Two of the 500-m bands (469 and $555 \mathrm{~nm}$ ) have similar wavelengths to the saturating lower spatial resolution bands, albeit spectrally broader (see Fig. S1, as shown in 


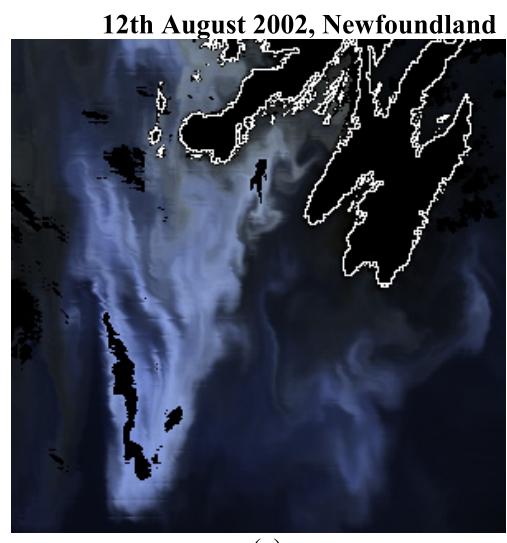

(a)

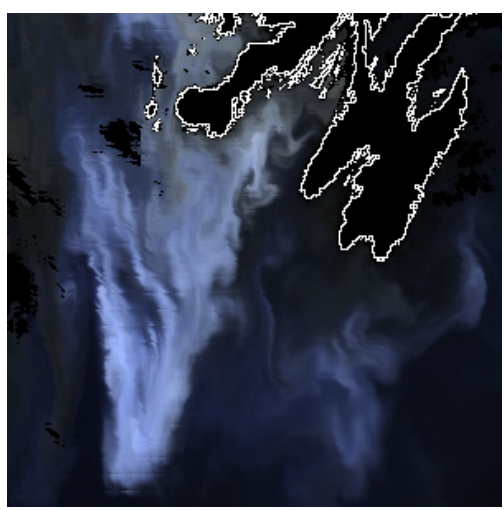

(d)

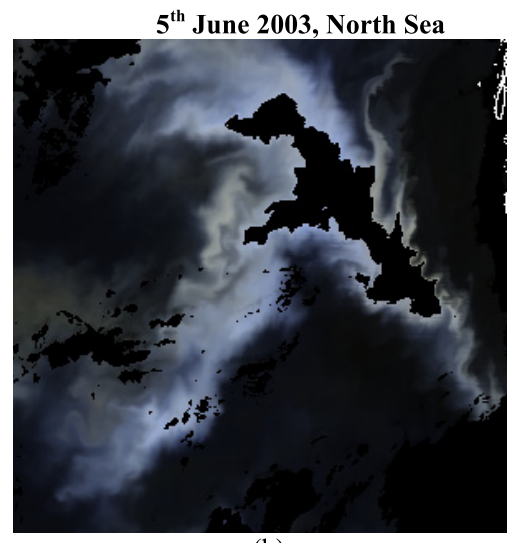

(b)

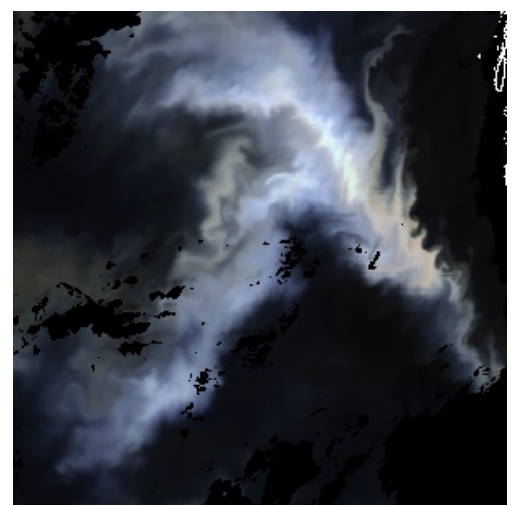

(e)

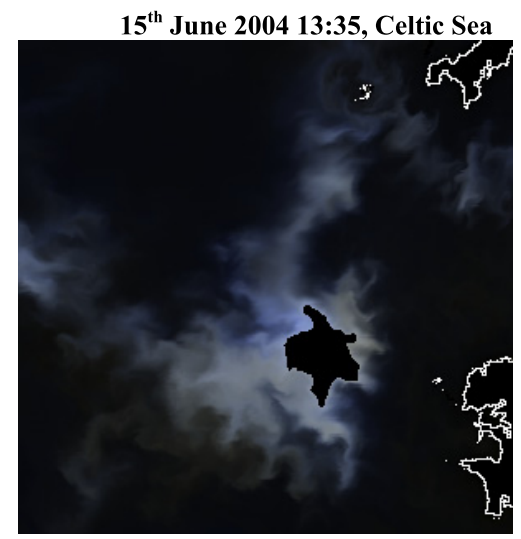

(c)

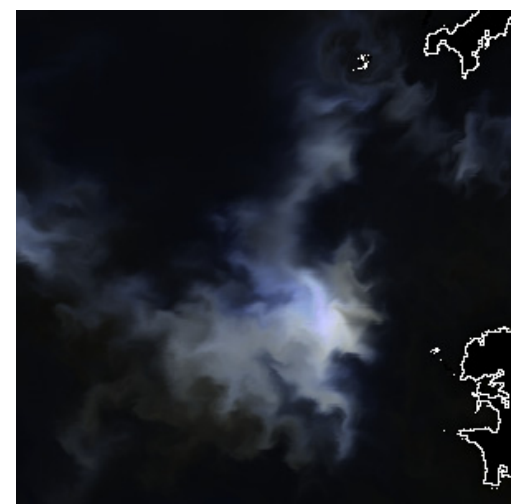

(f)

Fig. 2. MODIS-Aqua Level $2 R_{\mathrm{RS}}$ composites (red $=547 \mathrm{~nm}$, green $=531 \mathrm{~nm}$, and blue $=488 \mathrm{~nm}$ ). (a)-(c) Original reflectances, with unprocessed pixels shown as black. (d)-(f) Same composites after correction. Note that pixels around clouds and coastlines remain unprocessed.

the Supplementary Material). MODIS 1-km L1B files contain these bands aggregated to $1-\mathrm{km}$ resolution, such that each aggregated pixel corresponds to a pixel in the 1-km ocean color bands [10]. If a relationship between the 500-m bands and the ocean color bands can be established using unsaturated data, the relationship can be extrapolated to reconstruct the saturated ocean color data at $1-\mathrm{km}$ resolution from the corresponding 500-m data. This method builds on the theory and approach of [11].

\section{METHOD}

Level 1A granules of the three scenes were downloaded from www.oceancolor.gsfc.nasa.gov (2013.1 reprocessing) on November 11, 2014 and processed to Levels 1B and 2 using version 7.2 of NASA's SeaDAS processing package using default SeaDAS settings. For each scene, we plotted the valid ocean color L1B $L_{t}$ against $L_{t}$ in the spectrally nearest 500-m band. We only plotted pixels for which the L2 $R_{\mathrm{RS}}$ was nonzero, to eliminate cloud pixels and saturated ocean color pixels [Fig. 3(a)-(c)]. This showed the bands to be well correlated, but with some scatter, the main cause of which was identified as pixels at the edges of noncoccolithophore bright objects such as clouds and some land, identifiable by high radiances in the near-infrared at $869 \mathrm{~nm}$ [ $L_{t}(869)$, Fig. 3(g)-(i)]. We therefore used the STLIGHT flag to remove these pixels. This flags all pixels within a $7 \times 5$ box (across track $\times$ along track) of pixels with the HILT or cloud/ice (CLDICE) flag set. Unfortunately, simple application of the STLIGHT flag also eliminates pixels close to the bloom pixels masked by the HILT flag, which are likely to be the most useful pixels for extrapolation. To prevent this, the STLIGHT flag was recalculated using only pixels with the CLDICE flag set and any land pixels for which the HILT flag was set. Hence, pixels close to cloud or bright land will be masked, but not those close to bright ocean pixels or dark land pixels. This resulted in a high degree of correlation between the 500-m bands and the corresponding ocean color bands. However, when one was simply regressed against the other, a slight deviation from the fit curve could be seen at the largest radiance levels, just where the best fit is needed. This occurred for both linear and quadratic fits (not shown).

Therefore, to enhance the fit at high PIC, an attempt was made to regress the $1-\mathrm{km}$ bands against the $500-\mathrm{m}$ bands, weighted by PIC. However, this revealed the problem that the PIC algorithm actually consists of two distinct algorithms, resulting in two distinct PIC groupings in the regressions. By default, MODIS uses a two-band algorithm (calcite_2b) [1], estimating backscatter due to PIC from normalized water leaving radiance (nLw) at 443 and $547 \mathrm{~nm}$. If these bands saturate or have negative nLw, it switches to a three-band algorithm (calcite_3b) [6], which estimates backscatter due to PIC from $L_{t}$ in the red and near-infrared and uses its own atmospheric correction, independent of the corrected bands. To avoid regression artifacts due to this 
$488 \mathrm{~nm}$ vs. $469 \mathrm{~nm}$

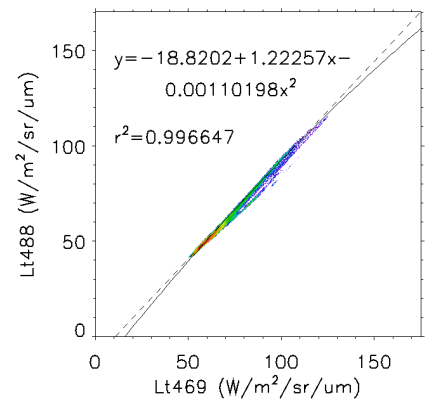

(a)

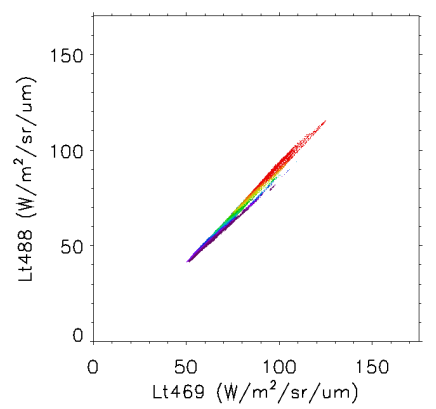

(d)

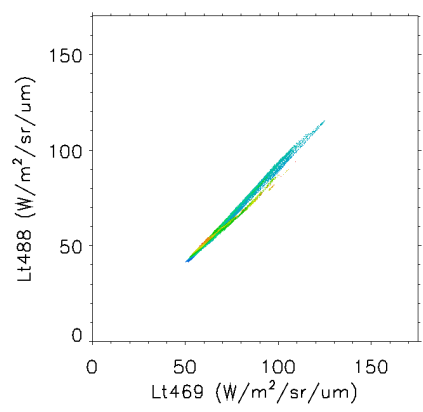

(g)
$531 \mathrm{~nm}$ vs. $555 \mathrm{~nm}$

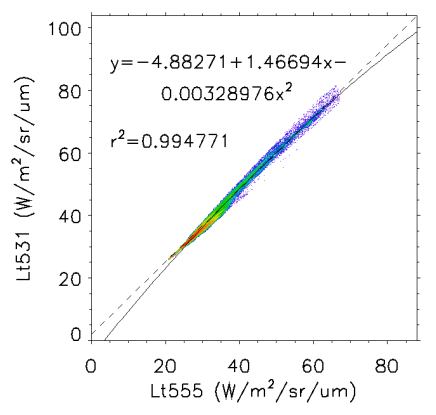

(b)

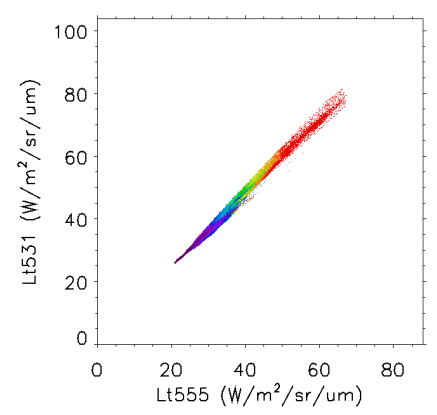

(e)

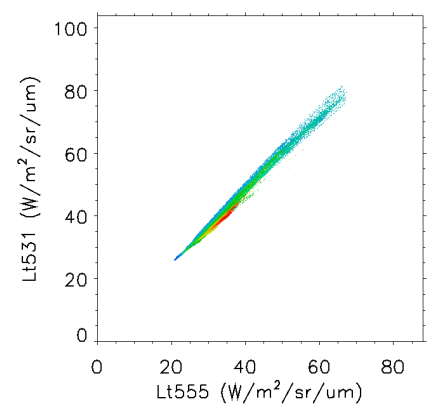

(h)
$547 \mathrm{~nm}$ vs. $555 \mathrm{~nm}$

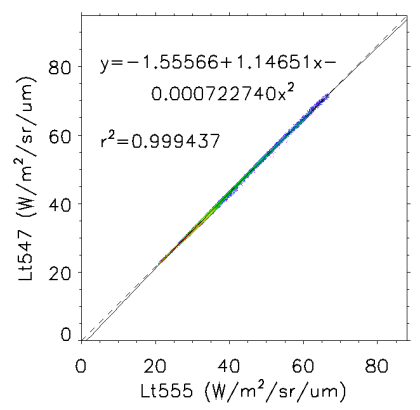

(c)

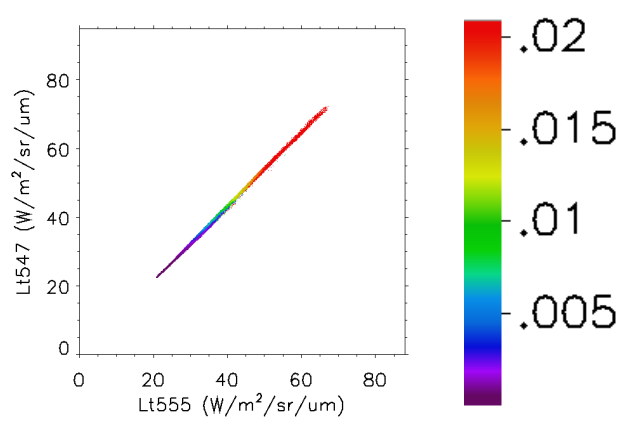

(f)

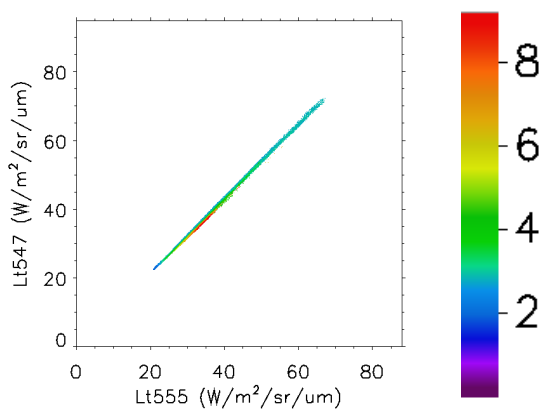

(i)

Fig. 3. (a)-(c) Scatter plots of top of atmosphere radiance on June 15, 2004. The vertical axis denotes a 1-km band (488, 531, and 547 nm) and the horizontal axis denotes a $500-\mathrm{m}$ band $(469,555$, and $555 \mathrm{~nm})$. Colors toward the red end of the spectrum denote high frequency, i.e., many pixels with that combination of radiances. The dashed line is a linear fit weighted by calcite_3b [see (d)-(f)], and the solid line and the text are a quadratic fit weighted by calcite_3b. (d)-(f) are similar to (a)-(c), but in this case colors toward the red end of the spectrum denote high calcite_3b. The scale bar shows calcite_3b in $\mu$ mol/m ${ }^{3}$. (g)-(i) are similar to (a)-(c), but in this case colors toward the red end of the spectrum denote high radiance in the near-infrared at $869 \mathrm{~nm}$. The scale bar shows $L_{t}$ at $869 \mathrm{~nm}$ in $\mathrm{W} / \mathrm{m}^{2} / \mathrm{sr} / \mu \mathrm{m}$.

switching, we weighted the regressions using only calcite_3b, which is equal to the PIC product at high PIC and does not saturate. Results of this linear regression are shown in Fig. 3(a)-(c) as a dotted line. The linear regression can be seen to slightly miss the data trend at the highest radiances, most noticeably at $488 \mathrm{~nm}$, so a quadratic fit was used, shown in Fig. 3(a)-(c) as a solid line. However, henceforth when we refer to PIC this means the combined 2 and 3 band product.

We then corrected all ocean pixels for which any ocean color band was saturated and neither the modified STLIGHT nor CLDICE flags were set, by applying the quadratic regression to the corresponding aggregated 500-m data. Results are shown in Fig. 2(d)-(f) for comparison with Fig. 2(a)-(c). Finally, we used the corrected L1B file to generate a new L2 file using SeaDAS 7.2, with default SeaDAS settings except that HILT masking was switched off. The original $R_{\mathrm{RS}}$ RGB composites are shown in Fig. 1(a)-(c), and the corrected $R_{\mathrm{RS}}$ RGB composites are shown in Fig. 1(d)-(f). The original PIC product with L2 flags masked is shown in Fig. 4(a)-(c), calcite_3b with L2 flags masked in Fig. 4(d)-(f) and with L3 flags masked in Fig. 4(g)-(i) (this is the product that is used to form L3 composites), and calcite_3b after L1B 
(a)

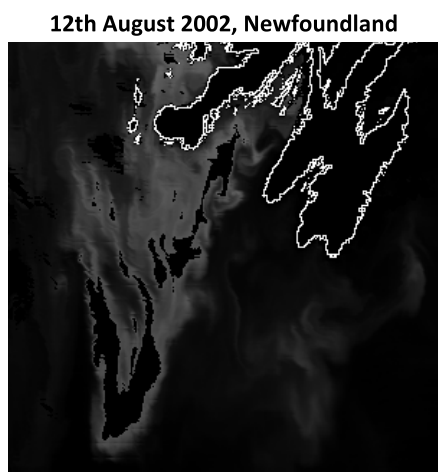

(d)

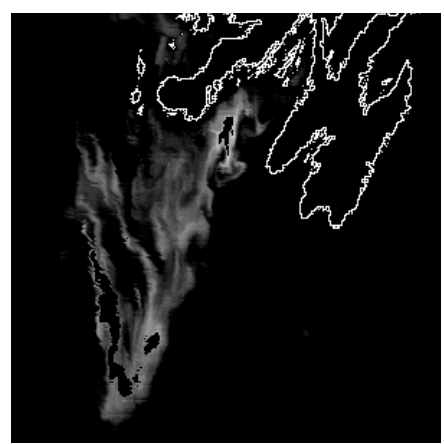

(g)

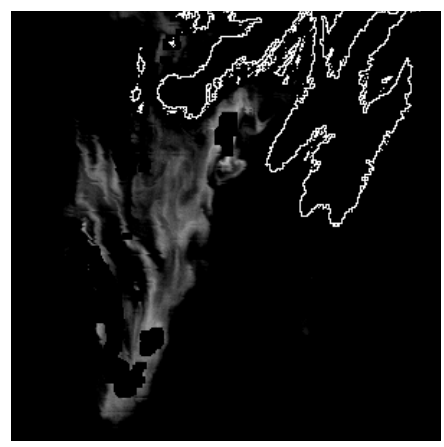

(j)

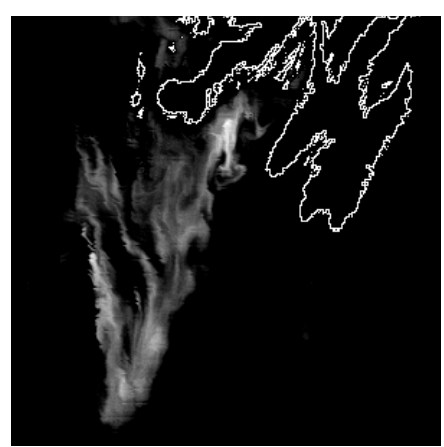

(b)

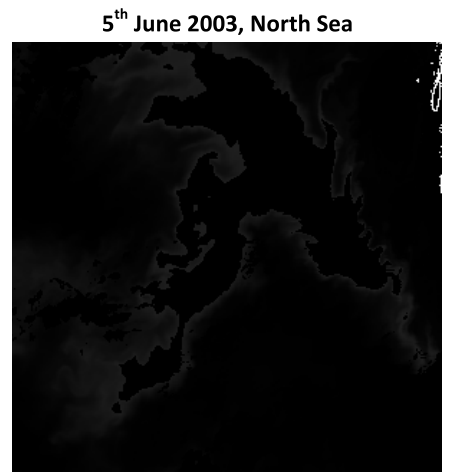

(e)

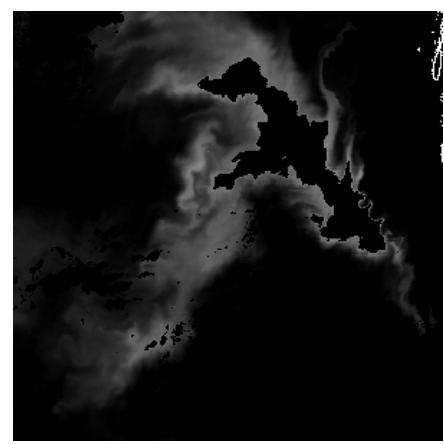

(h)

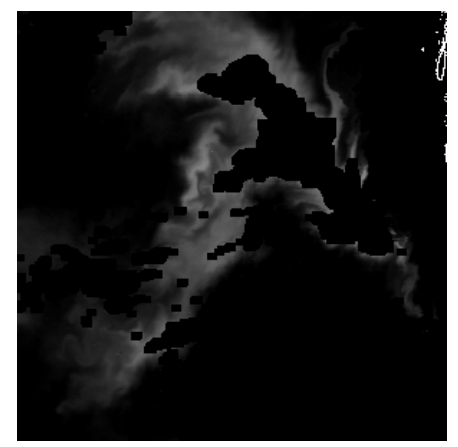

(k)

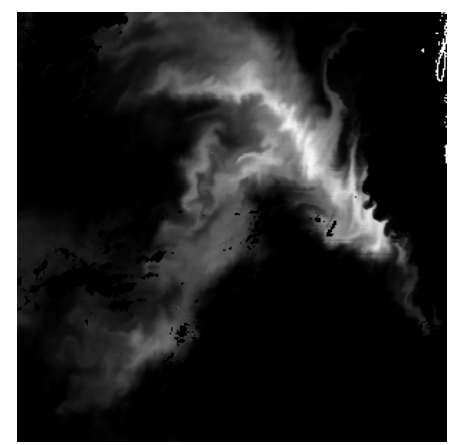

(c)

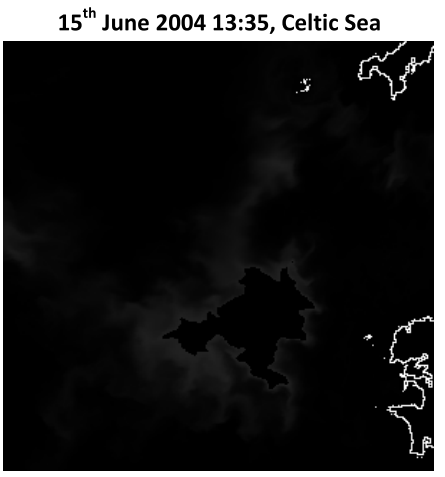

(f)

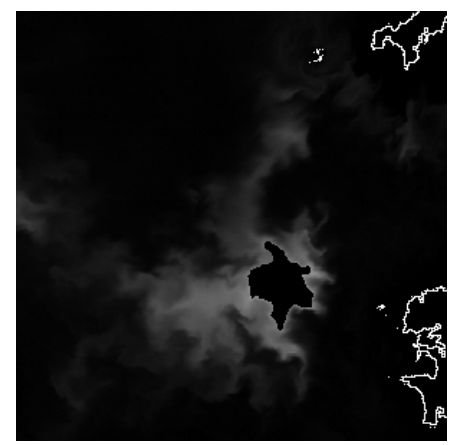

(i)

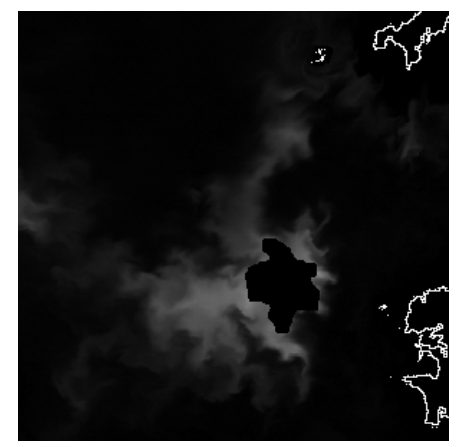

(1)

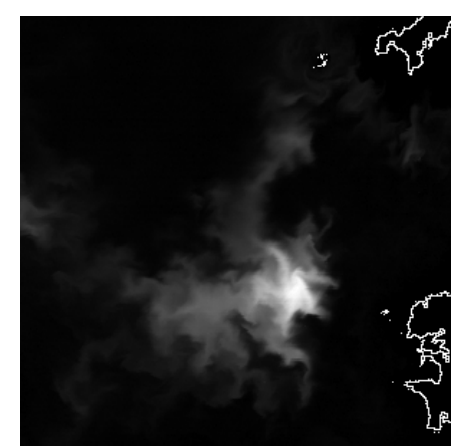

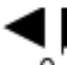

0.2

0.4

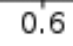

0.8

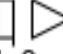

Fig. 4. (a)-(c) Standard PIC product in $\mu \mathrm{mol} / \mathrm{m}^{3}$. (d)-(f) Calcite_3b product. (g)-(i) Calcite_3b product with level 3 masking applied (used to create level 3 composites). (j)-(1) Corrected calcite_3b product. The scale bar shows the ratio of PIC to maximum PIC within each column, which varies over an order of magnitude between columns (0.0094, 0.0116, and $0.0901 \mu \mathrm{mol} / \mathrm{m}^{3}$ from left to right). Comparison within a column shows the extent to which saturation excludes the most intense parts of each bloom.

correction and STLIGHT modification with L2 flags masked in Fig. 4(j)-(1). Note that calcite_3b does not use the corrected bands, so the correction simply prevents calcite_3b data from being erroneously masked. Close inspection of Figs. 1(d)-(f) and 2(d)-(f) shows no obvious artifacts or discontinuities due to the hole-filling approach.
The threshold of $R_{\mathrm{RS}}$ or PIC at which saturation occurs is dependent on the scene geometry and conditions (the conversion from $L_{t}$ to $R_{\mathrm{RS}}$ and geophysical products is the purpose of atmospheric correction), but our sample data can give us an estimate. In the three cases above, the maximum $R_{\mathrm{RS}}$ and calcite_3b in the uncorrected data had ranges 


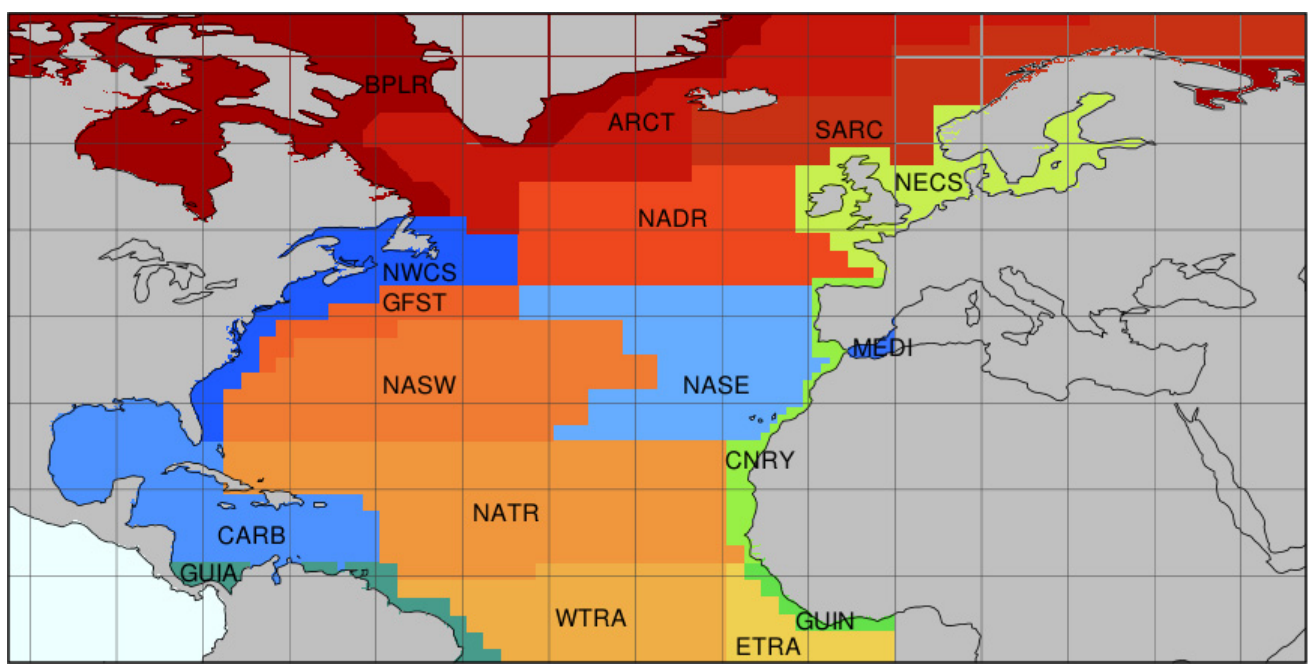

(a)

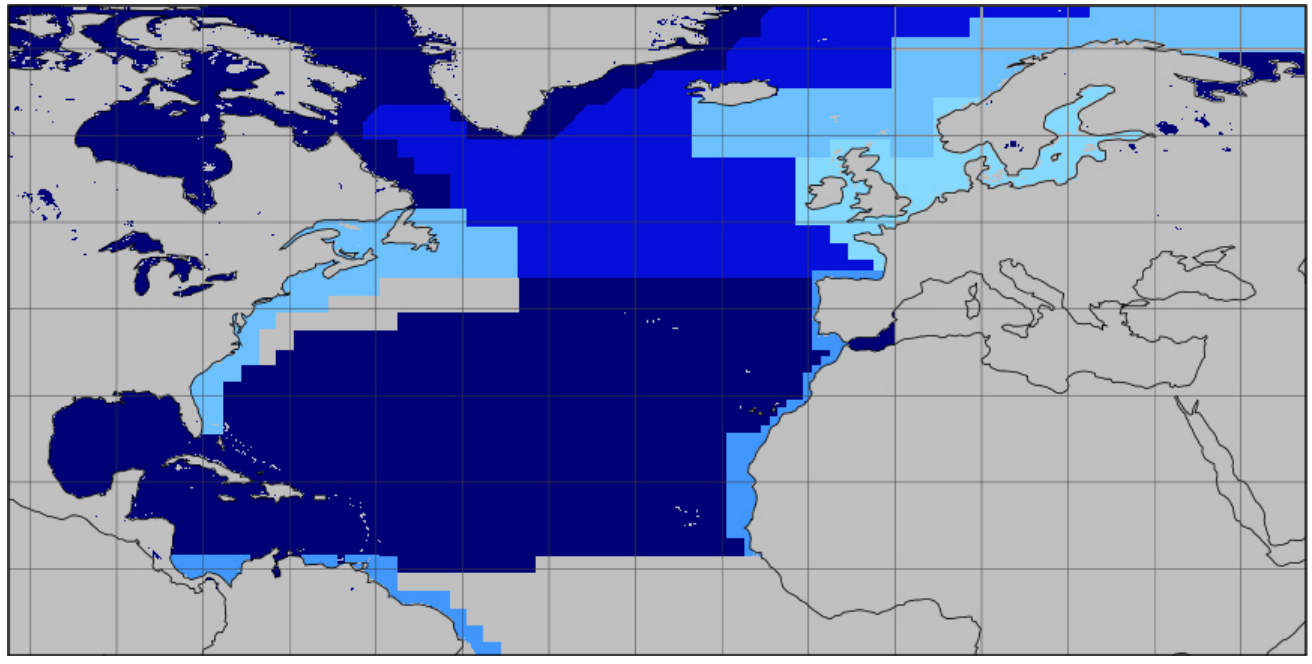

(b)

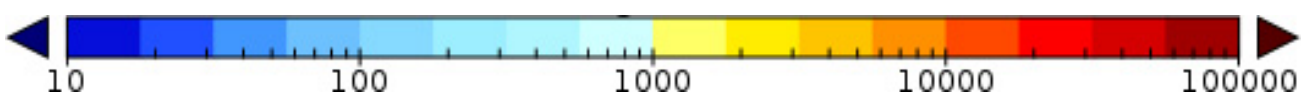

Fig. 5. (a) Definitions of the North Atlantic Longhurst provinces. (b) Maximum monthly effect on mean PIC ( $\mu$ mol $/ \mathrm{m}^{3}$ ) due to correction at level 3 in each Longhurst province on the same scale as Fig. S2 (as shown in the Supplementary Material), with depths less than $50 \mathrm{~m}$ masked.

of $0.048-0.051 \mathrm{sr}^{-1}$ and $0.025-0.058 \mathrm{~mol} / \mathrm{m}^{3}$, respectively, while in the corrected data the ranges were $0.055-0.063 \mathrm{sr}^{-1}$ and $0.030-0.098 \mathrm{~mol} / \mathrm{m}^{3}$. The $R_{\mathrm{RS}}$ range is comparable with optical field data in intense blooms in the Western English Channel in 1999 and the Celtic Sea in 2002, in which the maximum $R_{\mathrm{RS}}$ was $0.048-0.061 \mathrm{sr}^{-1}$ (T. Smyth, personal communication, Mar. 2016).

\section{ANALYSIS OF REGIONAL IMPACT}

Simple estimation of the regional impact of this correction is difficult, since the effect is large but rare and localized. At the very least, it requires systematic correction of all scenes covering the region of interest over one coccolithophore bloom season, preferably several, since the occurrence of intense coccolithophore blooms is highly variable from year to year. The effect on any time series will depend on how the data are constructed, e.g., a method using only L2 masking is likely to be less affected than one using L3 masking, in which more peak bloom data are usually lost, and a shorter time step, such as 8-day composites, will result in larger peak effects than a longer averaging period such as monthly composites.

We applied the correction to the entire MODIS archive over the North Atlantic using SeaDAS 7.1 (note this is an earlier version of SeaDAS than used in the three examples abovethis was a major computing task and was undertaken before SeaDAS 7.2 was available). We estimated the impact of the identified error by using the three example scenes to find the largest unsaturated radiance observed in the scene, which we used as an estimate of the radiance threshold at which each of the ocean color bands saturates, provided some saturated pixels are present. This threshold should be scene independent, but can drift as the instrument ages. Thresholds for the three scenes and three wavelengths are shown in Table S1 (as shown in the Supplementary Material). Also shown is the mean threshold over the three years at each wavelength, which was used to estimate the impact on all years. 


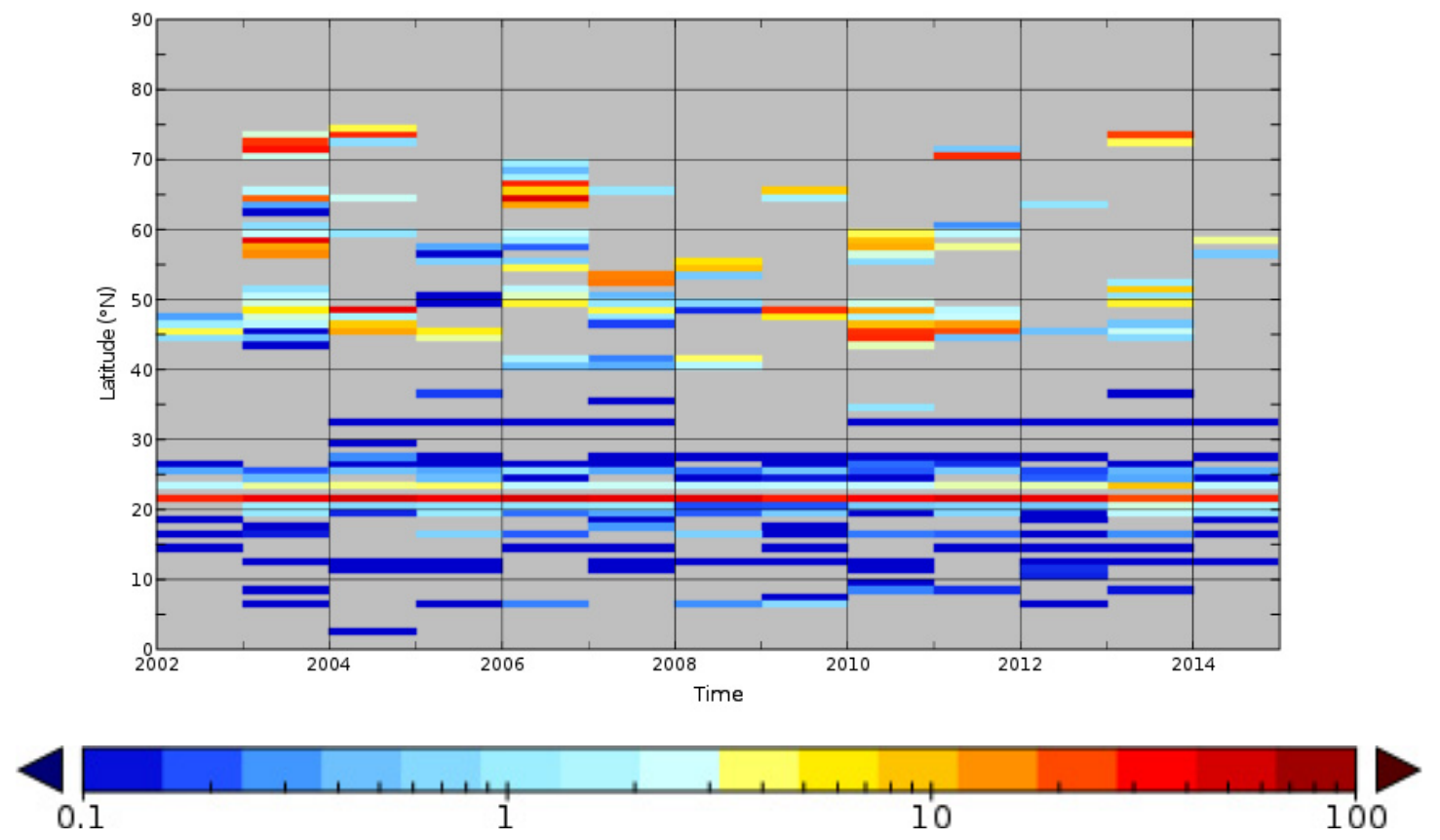

Fig. 6. Mean effect of the correction on level 3 PIC $\left(\mu \mathrm{mol} / \mathrm{m}^{3}\right)$ in each year and one-degree latitude band.

Results were mapped to a geographic projection with a spatial resolution of $9 \mathrm{~km}$ at the equator, or about $5 \operatorname{arc}$ minutes. Two regions were defined, one from $0^{\circ} \mathrm{N}$ to $90^{\circ} \mathrm{N}$, $105^{\circ} \mathrm{W}$ to $0^{\circ} \mathrm{W}$ (the central North Atlantic) and the other from $48^{\circ} \mathrm{N}$ to $90^{\circ} \mathrm{N}, 0^{\circ} \mathrm{E}$ to $105^{\circ} \mathrm{E}$ (northern European seas). All passes that intersected either region were corrected, and both uncorrected and corrected data with L2 and L3 masking were map projected and binned into monthly and annual composites of the mean of all passes in each pixel and time period. The difference between uncorrected and corrected binned data shows the effect of the correction on the composites. A map of the mean L3 PIC over the whole time series is shown in Fig. S2(a) (as shown in the Supplementary Material), and the effect of the correction on mean L3 PIC is shown in Fig. S2(b) (as shown in the Supplementary Material), showing a correction effect that is highly localized. Surprisingly, the effect occurred strongly in the Barents Sea, north of Norway, up to about $73^{\circ} \mathrm{N}$, where strong blooms are observed but the low sun elevation reduces direct solar illumination to about $30 \%$ of its value at the equator, so blooms need to be correspondingly more reflective to cause saturation.

Many of the strongest effects are seen close to the coast, e.g., the northern coast of South America and the west African coast, or in shallow offshore waters such as the shelves of the Gulf of Mexico, or the west of Bermuda and around the Turks and Caicos Islands, both of which have large expanses of shallow, clear water with coral reefs, and bright sand. In these areas, high radiance could be caused by bottom reflectance or suspended sediment, causing both an overestimate of PIC and an increased likelihood of saturation. To eliminate these effects, a bathymetry map of the North Atlantic in the above projection was produced from the higher resolution GEBCO_08 one-minute grid (www. gebco.net/data_and_products/gridded_bathymetry_data/gebco _one_minute_grid/, downloaded on December 14, 2009).
The minimum depth of all GEBCO_08 grid cells in a given map cell was used in order to eliminate residual effects in map cells containing both shallow and deep water, and all map cells with minimum depth less than $50 \mathrm{~m}$ were masked. This depth limit represents a balance between excluding suspended sediment, especially resuspended coccoliths or diatom frustules [12], and including as many genuine coccolithophore blooms as possible. Coccolithophore blooms undoubtedly occur in waters shallower than $50 \mathrm{~m}$, and suspended sediment effects may be seen in deeper waters (see [12]), especially where advected from shallow waters by river plumes. Results are shown in Fig. S2(c)-(d) (as shown in the Supplementary Material) for comparison with Fig. S2(a)-(b) (as shown in the Supplementary Material). It can be seen from Fig. S2(c) (as shown in the Supplementary Material) that many coastal and river plume artifacts have been removed by this process. Masked results are shown henceforth.

To assess the impact on regional scales, Table S2 (as shown in the Supplementary Material) summarizes the effect on the mean PIC in the Longhurst provinces [13] covered by the mapped region over the whole time series and at annual and monthly intervals. The Atlantic provinces intersecting the mapped region are shown in Fig. 5(a). The relative effect on the whole mapped region was small, less than $1 \%$ annually and $2 \%$ in any month. The mean L3 PIC over the whole region and time series was $350 \mu \mathrm{mol} / \mathrm{m}^{3}$. Larger effects were seen on the province scale, with a maximum monthly effect of $156 \mu \mathrm{mol} / \mathrm{m}^{3}$ (7\% of the corrected mean PIC in that province and month) in the Northeast Atlantic Continental Shelf province in June 2003, and monthly effects greater than $48 \mu \mathrm{mol} / \mathrm{m}^{3}$ were observed in the NWCS (10\%), CNRY (12\%), SARC (5\%), and GUIA (10\%) provinces [see Fig. 5(a) and Table S2, as shown in the Supplementary Material]. All other provinces had maximum effects 
less than $16 \mu \mathrm{mol} / \mathrm{m}^{3}$. The provinces and their maximum effect at L3 in any month are shown in Fig. 5(b).

To assess whether the local effects were caused by one-off events or recurred in other years, at each pixel the annual saturation effects in all years were summed and divided by the maximum annual effect. This gives a measure of the number of years in which the effect occurred with a similar magnitude. For instance, one very large annual effect with much smaller effects in other years will have a value close to 1. This number is shown in Fig. S3 (as shown in the Supplementary Material), which shows that the saturation effect recurs in certain locations in multiple years with similar magnitude.

It has been suggested that coccolithophore blooms have moved northward over the last 10-15 years [14], so it would be interesting to see if there is any evidence of such a shift in the strongest blooms selected by this effect. Fig. 6 shows a Hovmöller plot of the mean change in L3 PIC due to saturation in a given year and one-degree latitude band as function of year and latitude. The plot shows the expected strong spatial and temporal variability, but no evidence of a northward trend in these extreme blooms.

\section{DISCUSSION AND CONCLUSION}

The method seems to work well for the three test scenes, with very plausible-looking variations in $L_{t}, R_{\mathrm{RS}}$, and PIC in the reconstructed data. Direct validation of this method would require sea truth measurements of $R_{\mathrm{RS}}$ and/or PIC at the peak of the strongest coccolithophore blooms at the time of a MODIS overpass. Given that such data are scarce in any coccolithophore blooms, this seems unlikely. In the three example scenes, affected pixels constitute $1 \%, 2 \%$, and $0.3 \%$ of the total ocean pixels in the MODIS granule with valid L2 data, so even if a ship were within the scene taking the right measurements, it would be unlikely to be in the affected area by chance. Strong blooms can persist for weeks [15], so perhaps the best chance would be for a rapid response vessel to be on standby in a region where saturating coccolithophore blooms occur in multiple years, ready to be directed to the peak of the bloom using satellite data. This would require significant resources, and would still be difficult. For instance, a dedicated coccolithophore cruise was in the area of the 2004 Celtic Sea bloom at the time, and was guided by satellite imagery to the location of the bloom peak [16]. However, they measured the area of saturation 12 days before saturation, on June 3, 2004, and were elsewhere in the bloom when saturation occurred. This approach will be even more challenging if coccolithophore blooms are changing location [14], though we could find no evidence of this in blooms strong enough to cause saturation.

The regional analysis reveals that blooms strong enough to cause saturation are rare and confined to a few well-defined areas of the North Atlantic, and there are a small number of highly localized areas where strong blooms recur in multiple years in the same geographical location, suggesting that local forcing is driving their formation, e.g., at the shelf edge. The effect of saturation on annual mean PIC is small on a basin scale, but can be regionally significant, especially at monthly time scales. Generally, the more intense the bloom is, the higher the increase in the in-water $\mathrm{pCO}_{2}$, suggesting that studies which focus on these regions should at least be aware of the missing data when estimating the uncertainties within these PIC data and when interpreting the condition of the complete marine carbon system. Equally, any analyses using these PIC data to estimate the influence that coccolithophores have on the marine carbonate system in the North Atlantic, and other oceanic regions where coccolithophores are prevalent, is likely to result in an underestimation. For example, Fig. 6 shows the intense blooms that generally occur at higher latitudes, which are typically characterized by colder waters. These colder waters have the ability to absorb more $\mathrm{CO}_{2}$ (a process predominantly driven by solubility). Thus these intense blooms are likely to reduce the potential for these regions to take up $\mathrm{CO}_{2}$, and this influence has yet to be highlighted or characterized. Indeed, the strongest of these events are currently missing from the MODIS archive due to the saturation issue addressed here.

It is worth considering the extent to which atmospheric path radiance contributes to the correlations found, as this usually dominates $L_{t}$ over the oceans. However, this paper concerns special cases where $L_{t}$ far exceeds values expected from a clear maritime atmosphere, and the regressions used are weighted toward the brightest pixels. Pixels that are potentially affected more strongly by atmospheric effects are masked due to their brightness in the near infrared response (or proximity to such pixels), so we have no reason to expect a large atmospheric contribution. Also, coccolithophore blooms tend to be visible from space during periods of atmospheric stability, decreasing the likelihood of significant atmospheric variability. There remains the possibility that the coccolithophore bloom creates an associated region of high aerosol concentration, but we consider this unlikely to be significant on the timescale of a typical coccolithophore bloom. The finescale structures seen in Fig. 1 are typical of in-water, rather than aerosol, effects.

The PIC values estimated using this correction contain larger uncertainties than those generated directly from the $1-\mathrm{km}$ measurements, and hence, should be used with care. However, the uncertainties are difficult to quantify. As the 1-km bands approach saturation, the linearity between level 1A digital counts and L1B radiances starts to break down at about $80 \%$ of the saturation radiance [17], resulting in increased uncertainty in the L1B radiance. In addition, the 500-m bands have higher uncertainty than the $1-\mathrm{km}$ bands, including significant digitization error due to the lower sensitivity of these bands. These effects, which are quantified as uncertainty products in MODIS data, could be incorporated into the regressions to give an uncertainty in the extrapolated $L_{t}$. It is less clear how to convert this into an uncertainty in $R_{\mathrm{RS}}$ and PIC without incorporating the correction into the MODIS processing. However, it should be noted that none of these effects is expected to produce a significant bias in $L_{t}$ and (with lower confidence due to the nonlinear algorithms used) in $R_{\mathrm{RS}}$ and PIC. Hence, we consider the use of this method to correct the known bias due to the missing PIC data to be valid. In the absence of a rigorous error analysis or validation, the individual PIC values 
estimated by this method should be treated with caution, and we recommend that they only be used in aggregate, e.g., to study the impact of a bloom as a whole or (as we have done here) to correct bias in regional PIC estimates.

The algorithm could be further developed by interpolating spectrally between the 500-m bands and regressing against the interpolated value, rather than the nearest 500-m band. Another refinement would be to treat a saturating bloom spanning two granules using the same regressions, in order to avoid artifacts at the boundary. If we are only interested in PIC, and not in $R_{\mathrm{RS}}$ or $L_{t}$, a simplification could be to set saturated $L_{t}$ to a generic high but unsaturated value, and rely on the fact that saturated pixels are almost certain to use calcite_3b, which does not use the bands likely to saturate. In this case, care should be taken to ensure that calcite_2b is never used on such pixels. However, simply leaving the pixels saturated and switching off the HILT and STLIGHT masks would not work. Though it would enable calculation of PIC using calcite_3b, it would also process cloud-affected pixels normally masked by STLIGHT, which would be incorporated into subsequent composites.

\section{REFERENCES}

[1] W. M. Balch, H. R. Gordon, B. C. Bowler, D. T. Drapeau, and E. S. Booth, "Calcium carbonate measurements in the surface global ocean based on Moderate-Resolution Imaging Spectroradiometer data," J. Geophys. Res., Oceans, vol. 110, Jul. 2005, Art. no. C07001.

[2] M. D. Iglesias-Rodríguez et al., "Representing key phytoplankton functional groups in ocean carbon cycle models: Coccolithophorids," Global Biogeochem. Cycles, vol. 16, no. 4, pp. 47-1-47-20, 2002.

[3] J. D. Shutler et al., "Coccolithophore surface distributions in the North Atlantic and their modulation of the air-sea flux of $\mathrm{CO}_{2}$ from 10 years of satellite Earth observation data," Biogeosciences, vol. 10, no. 4, pp. 2699-2709, 2013.

[4] A. J. Watson et al., "Tracking the variable North Atlantic sink for atmospheric $\mathrm{CO}_{2}$," Science, vol. 326, no. 5958, pp. 1391-1393, 2009.

[5] T. Takahashi et al., "Climatological mean and decadal change in surface ocean $\mathrm{pCO}_{2}$, and net sea-air $\mathrm{CO}_{2}$ flux over the global oceans," Deep Sea Res. II, Topical Studies Oceanogr., vol. 56, pp. 554-577, Apr. 2009.

[6] H. R. Gordon, G. C. Boynton, W. M. Balch, S. B. Groom, D. S. Harbour, and T. J. Smyth, "Retrieval of coccolithophore calcite concentration from SeaWiFS Imagery," Geophys. Res. Lett., vol. 28, no. 8, pp. 1587-1590, 2001.

[7] T. J. Smyth, T. Tyrrell, and B. Tarrant, "Time series of coccolithophore activity in the Barents Sea, from twenty years of satellite imagery," Geophys. Res. Lett., vol. 31, Jan. 2004, Art. no. L11302.

[8] T. S. Moore, M. D. Dowell, and B. A. Franz, "Detection of coccolithophore blooms in ocean color satellite imagery: A generalized approach for use with multiple sensors," Remote Sens. Environ., vol. 117, pp. 249-263, Feb. 2012.

[9] J. D. Shutler, M. G. Grant, P. I. Miller, E. Rushton, and K. Anderson, "Coccolithophore bloom detection in the north east Atlantic using SeaWiFS: Algorithm description, application and sensitivity analysis," Remote Sens. Environ., vol. 114, no. 5, pp. 1008-1016, 2010.

[10] M. Nishihama et al., "MODIS level 1A Earth location: Algorithm theoretical basis document version 3.0," NASA Goddard Space Flight Center, Greenbelt, MD, USA, Tech. Rep. SDST-092, 1997.

[11] J. D. Shutler, P. E. Land, T. J. Smyth, and S. B. Groom, "Extending the MODIS $1 \mathrm{~km}$ ocean colour atmospheric correction to the MODIS $500 \mathrm{~m}$ bands and $500 \mathrm{~m}$ chlorophyll $-a$ estimation towards coastal and estuarine monitoring," Remote Sens. Environ., vol. 107, pp. 521-532, Apr. 2007.

[12] A. T. C. Broerse et al., "The cause of bright waters in the Bering Sea in winter," Continental Shelf Res., vol. 23, no. 16, pp. 1579-1596, 2003.

[13] A. Longhurst, S. Sathyendranath, T. Platt, and C. Caverhill, "An estimate of global primary production in the ocean from satellite radiometer data," J. Plankton Res., vol. 17, no. 6, pp. 1245-1271, 1995.

[14] A. Winter, J. Henderiks, L. Beaufort, R. E. M. Rickaby, and C. W. Brown, "Poleward expansion of the coccolithophore Emiliania huxleyi," J. Plankton Res., vol. 36, no. 2, pp. 316-325, 2013.
[15] J. Hopkins, S. A. Henson, S. C. Painter, T. Tyrrell, and A. J. Poulton, "Phenological characteristics of global coccolithophore blooms," Global Biogeochem. Cycles, vol. 29, no. 2, pp. 239-253, 2015.

[16] J. Harlay, A. V. Borges, C. Van Der Zee, B. Delille, R. H. M. Godoi, and L. S. Schiettecatte, "Biogeochemical study of a coccolithophore bloom in the northern Bay of Biscay (NE Atlantic Ocean) in June 2004," Prog. Oceanogr., vol. 86, pp. 317-336, Sep. 2010.

[17] C. Hu et al., "Dynamic range and sensitivity requirements of satellite ocean color sensors: Learning from the past," Appl. Opt., vol. 51, no. 25, pp. 6045-6062, 2012.

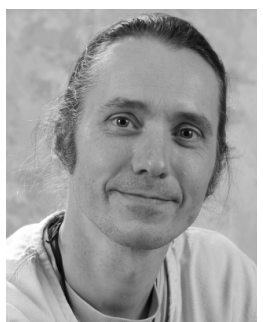

Peter E. Land was born in Cambridge, U.K., in 1964. He received the B.A. and M.A. degrees in physics from Oxford University, Oxford, U.K., in 1986, and the Ph.D. degree in remote sensing from Imperial College, London, U.K., in 1992.

From 1986 to 1988, he was a Scientific Officer with the U.K. Meteorological Office, Exeter, U.K. From 1992 to 1997, he was a Research Assistant with Space and Atmospheric Physics, Imperial College. From 1997 to 2000, he was a Researcher with the Department of Physical Geography, Stockholm University. Since 2000, he has been a Scientist with the Plymouth Marine Laboratory, Plymouth, U.K. He has authored over 23 peer-reviewed articles. His research interests include optical remote sensing of oceanic and coastal waters, air-sea gas fluxes, ocean acidification, coccolithophores, and phytoplankton phenology.

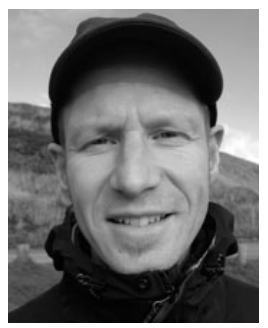

Jamie D. Shutler was born in Hampshire, U.K., in 1977. He received the B.Eng. (Hons.) degree in electronic engineering and the Ph.D. degree in computer vision from the University of Southampton, Southampton, U.K., in 1998 and 2002, respectively.

From 2000 to 2003, he was a Research Fellow at the University of Southampton. From 2003 to 2014, he was a Scientist and then a Senior Scientist at the Plymouth Marine Laboratory, Plymouth, U.K. Since 2014, he has been with the University of Exeter, Exeter, U.K., where he is currently an Associate Professor in earth observation. He has authored more than 30 articles. His research interests include in situ observations, satellite earth observation, and models to study and monitor the marine environment, particularly in relation to climate and water quality.

Dr. Shutler was a European Space Agency (ESA) Fellow from 2008 to 2010 and a member of three ESA expert teams.

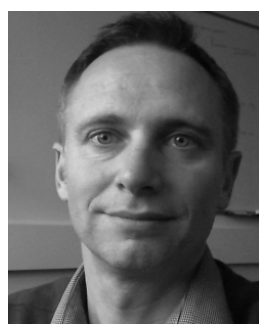

Timothy J. Smyth was born in Bristol, U.K., in 1972. He received the B.Sc. degree (First Class Hons.) in physics and meteorology and the Ph.D. degree in meteorology from the University of Reading, Reading, U.K., in 1994 and 1997, respectively, with a special focus on severe convective storms using polarization radar.

He was a Remote Sensing Scientist with the Plymouth Marine Laboratory (PML), Plymouth, U.K., in 1997, where he was involved in the newly launched SeaWiFS sensor. He is currently the Head of science for marine biogeochemistry and observations with PML. $\mathrm{He}$ involved in leading a team of around 20 people ranging from Ph.D. students to experienced senior scientists across a range of disciplines from air-sea exchange, nutrient cycling to molecular science within the broad remit of marine biogeochemistry. He has around 280 days of sea-going experience including being a Chief Scientist on two Atlantic Meridional Transect (2014 and 2015) expeditions between the U.K. and Falkland Islands. His brief also includes oversight of the Atlantic Meridional Transect as well as the Western Channel Observatory (WCO: both NERC National Capability) which he has been leading for the past decade. He has authored over 80 peerreviewed ISI papers. His research interests include broadly encompassed theoretical and experimental atmospheric, in-water optics, developing innovative technologies for automated marine measurements including the WCO buoys, ship emissions, and atmospheric aerosols. 